\title{
Does Chiari's Network affect atrial septal defect measurement?
}

\author{
Fatma Nur Gümrükçüoğlu ${ }^{1}$ and Hasan Ali Gümrükçüoğlu ${ }^{2^{*}}$ \\ ${ }^{1}$ Department of Anatomy, Faculty of Medicine, Yuruncu Yil Univesty, Van Turkey \\ ${ }^{2}$ Department of Cardiology, Faculty of Medicine, Yuzuncu Yil Univesty, Van Turkey
}

\section{Dear Editor;}

Chiari's Network is a congenital remnant in the right atrium. It was firstly reported by von Rokitansky in 1875, but earned its name from Hans Chiari (1), in 1897. Chiari's Network is found in $2-3 \%$ of normal hearts in literature, has no known purpose and is not pathological, but could be confused with valve disruption, vegetation or other mass lesion, particularly when associated with a suggestive clinical situation $(2,3)$. It is characterized by whip-like motion in the right atrium and exists to the wall of the right atrium in close proximity to the entrance of the inferior vena cava.

It maintains an embryonic right atrial flow pattern into adult life and directing the blood from the inferior vena cava toward the interatrial septum. It may also be associated with an increased prevalence of other congenital anomalies including atrial septal aneurysm, patent foramen ovale $(2,4)$ and facilitate paradoxical embolism (3).

Echocardiography is the most common imaging modality in detection of Chiari's Network. Werner et al. (5) published one of the first documented sonographic findings of Chiari's network. They described the sonographic features as a mobile curvilinear echogenic structure that appeared to extend from the right atrial wall at the opening of the inferior vena cava toward the interatrial septum.

We admit a patient (female, aged 24) presented with palpitation complaint who have no cardiovascular history. She had normal cardiovascular physical examination, blood pressure (systolic $134 \mathrm{mmHg}$, diastolic $72 \mathrm{mmHg}$ ) and normal electrocardiography findings at rest. We performed on echocardiography a very mobile structure in the right atrium, with the characteristic whip-like motion and atrial septal defect (ASD) $1.9 \mathrm{~cm}$ despite on transeusop-hageal echocardiography $2.2 \mathrm{~cm}$ was found. However, ASD diameter was different four chamber and bicaval views (Figure). Chiari's Network may confuse measurement of ASD diameter. In conclusion; we emphasize that Chiari's Network should be considered during measurement of ASD diameter.

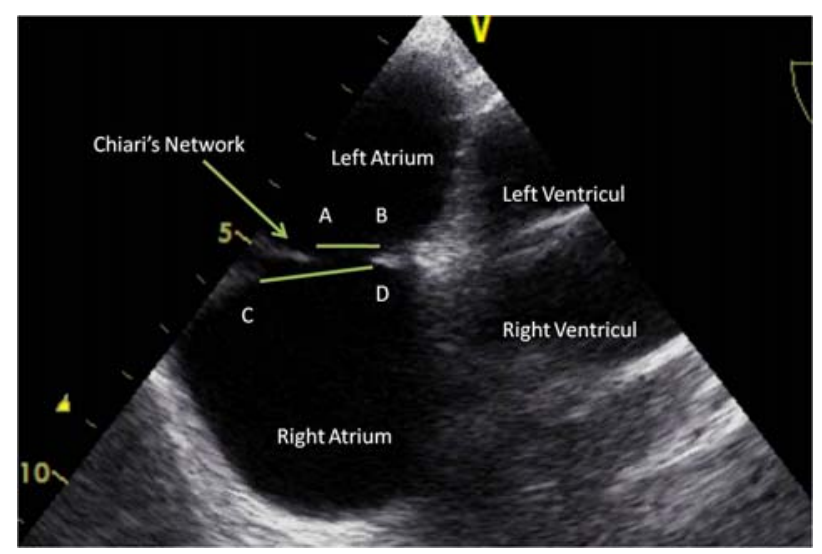

Fig. Transeusophageal Echocardiographic view, AB: Incorrect measurement of ASD diameter, CD: Correct measurement of ASD diameter.

\section{References}

1. Chiari H. UeberNetzbildungenimrechtenVorhofe des Herzens, Beitr z. path. Anat Uzallg Path 1897; 22: 17.

2. Werner JA, Cheitlin MD, Gross BW, Speck SM, Ivey TD. Echocardiographic appearance of the Chiari network: differentiationfrom right-heart pathology. Circulation 1981; 63: 1104-1109.

3. Naito M, Yu HC, Kim JH, et al. Topographic anatomy of the fetal inferior vena cava, coronary sinus, and pulmonary veins: Variations in Chiari's network. Clin Anat 2015; 28: 627-637.

4. ORBISON JL. Thrombosis of anomalous chordae in the right atrium; Chiari's network. Am Heart J 1949; 37: 119-122.

5. Werner JA, Cheitlin MD, Gross BW, Speck SM, Ivey TD. Echocardiographic appearance of the Chiari network: differentiation from right-heart pathology. Circulation 1981; 63: 1104-1109. 